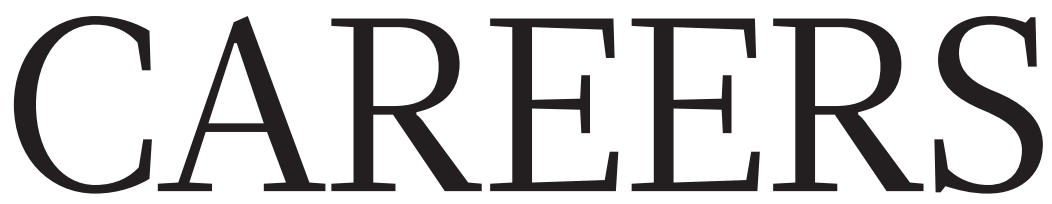

DIVERSITY Tackling barriers faced by underrepresented groups go.nature.com/2gjwkkn
CAREERS TOOLKIT A guide to the working world of science go.nature.com/2znrii1
SOCIAL Follow us on Twitter twitter.com/NatureCareers

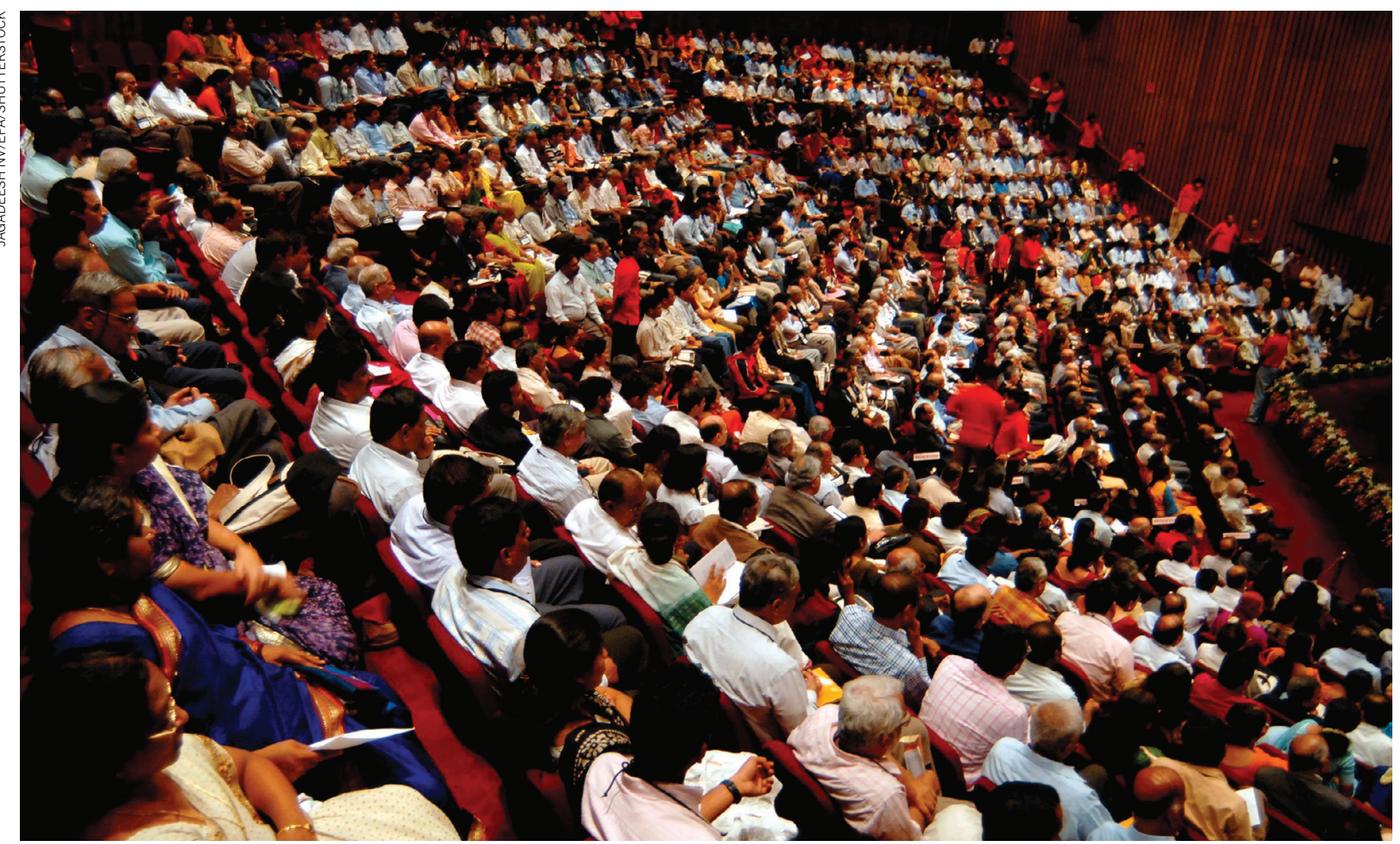

Programmes that give science talks in some of India's 22 languages hope to reach the $88 \%$ of citizens who don't speak English.

\title{
ENGAGEMENT
}

\section{Science for everyone}

\section{Researchers in India are giving talks and radio programmes in Tamil and other languages.}

\section{BY HARINI BARATH}

S cientists and policymakers across India are aiming to bring science to the nation's citizens and residents whose main language is not English. They're producing content such as articles and podcasts, and giving talks about discoveries and studies in health science, biology, biotechnology and astronomy in some of the nation's 22 official languages, including Hindi, Marathi, Kannada and Tamil.

As one of the languages used officially by the Indian government, English is largely considered to be the country's language for science - but just $12 \%$ of the nation's 1.3 billion citizens can speak and write it. Those who are trying to broaden the mix note that many more people will be able to access scientific content if it is available in other languages. "Speaking and writing in regional languages makes science more inclusive," says Maggie Inbamuthiah, founder of Mandram (which means 'platform' in Tamil), an organization based in Chennai that seeks to create a platform on which ideas in science and technology are communicated in regional languages, including Tamil and Kannada.

Initiatives to write about science and produce science-related content in languages other than English have been under way for several decades, as many urban schools and most higher-education institutions moved to an English-based curriculum. Those multilanguage efforts started to expand with the advent of the Internet, which has provided easy access to content, new media, platforms for distribution, and the ability to find collaborators and new audiences. Digital spaces and media have brought new players to the undertaking, and have re-energized those who have been involved in these efforts for years.

\section{LANGUAGE EVOLUTION}

Although digital platforms and social media help researchers and others to communicate scientific findings and discoveries to the public, any such endeavour is pointless if readers, viewers or listeners cannot speak or read that language. Few of India's languages have an up-to-date lexicon of scientific terms, and many researchers in the country have 
> long become accustomed to thinking and writing about science in English, says Inbamuthiah. Still, she notes, language is fluid and adaptable. "We enrich a language by adding new words," she says. "With time, we become more comfortable using them."

Today, the effort to communicate science in multiple languages has a number of participants. Kollegala Sharma, a zoologist and senior principal scientist at the Central Food Technological Research Institute (CSIR) in Mysuru, India, has been producing Janasuddi (jana means both smart and knowledge and suddi means news in Kannada), a weekly science podcast, since September 2017. The 20-minute episodes, which comprise science research, news and interactive sessions that might include audience questions or comments, is in Kannada and is circulated through the WhatsApp platform. Listeners mainly include public high-school teachers - about 1,000 , up from the 20 or so when Sharma first launched the programme. It's also available on public radio.

The Indian government is supporting the endeavour. K. VijayRaghavan, a molecular biologist and principal scientific adviser for the government, is a vocal proponent of making science accessible to people in their first language. He is working to provide increased funding and support for such efforts, and engages with many science communicators on social media, including Twitter.

\section{SPREADING INFLUENCE}

Other initiatives are emerging. Research Matters, a website that curates science news and articles in multiple languages and has more than 700,000 visitors, launched in November 2016. TED Talks India was launched in December 2017, and features prominent scientists who discuss topics such as neuroscience and astronomy in Hindi, the most widely spoken language in India. In January, the Indian Department of Science and Technology teamed with Doordarshan, a public service broadcaster, to launch two sciencecommunication initiatives, DD Science, shown on Doordarshan, and the Internet-based India Science. Both feature science-based programming in Hindi and English.

Others are also exploring the podcast realm. Last July, IndSciComm, an online science-communication collective, started Sea of Science, a podcast series in Hindi, Kannada, Marathi, Assamese and Tamil that talks about model organisms used in biological research. The series producers say that it is challenging to translate scientific terms and concepts into regional languages. "But working on them is just as much about love of language and wanting to reach out to people as it is an exercise of scientific understanding and language experience," says Shruti Muralidhar, a neuroscience postdoc at the Massachusetts Institute of Technology in Cambridge, and one of the producers. She says that they had to turn to

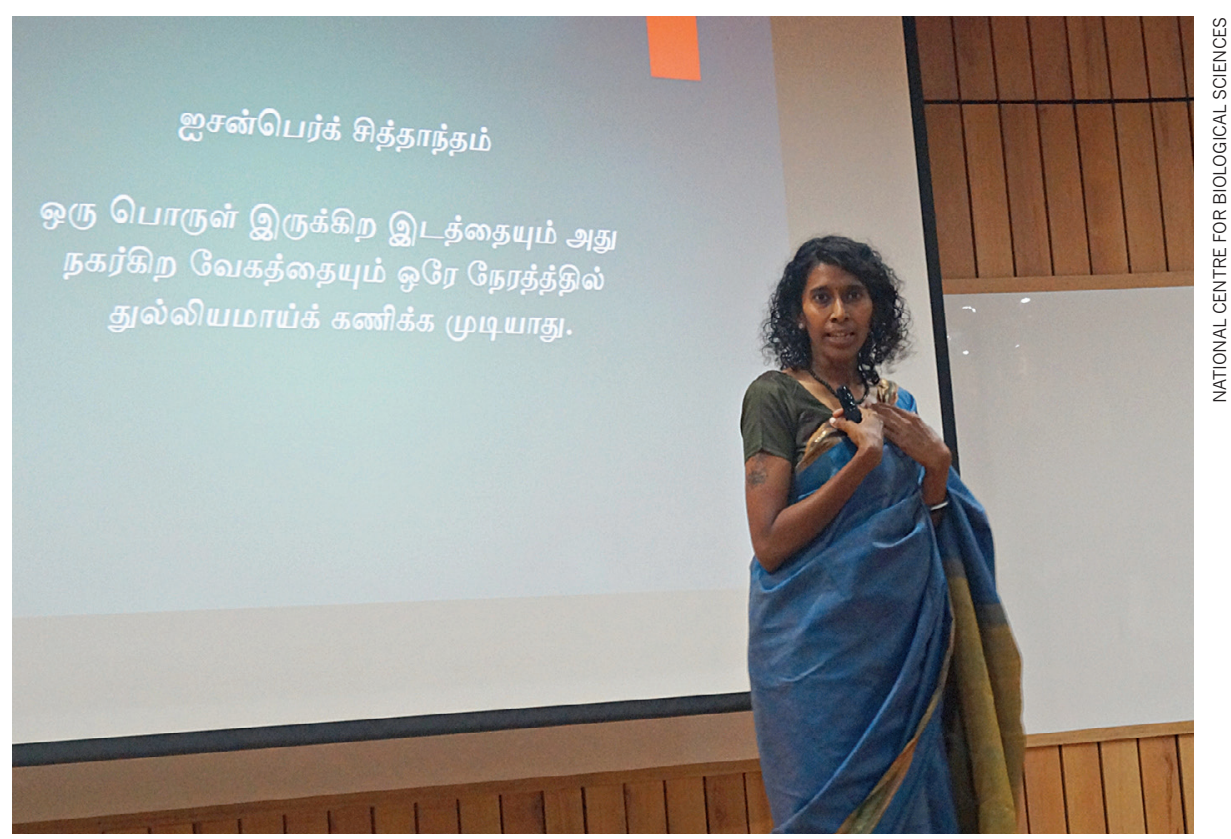

Maggie Inbamuthiah speaking at an event in Bengaluru, India.

online dictionaries, scientific lexicons and Google for support.

The producers also worked out a system of 'romanization' that helped them to keep some terms intact while maintaining the cadences and sentence structure specific to the language. While writing the script for the Tamil podcast, producer Abhishek Chari, a freelance science communicator in Cambridge, Massachusetts, had to translate the English word 'metabolism' into Tamil. Etymologically, it comes from the Greek word metabole (from metaballein, 'to change') plus the suffix '-ism'. But trying to directly translate this word into Tamil (possibly with the term maatram, meaning 'change')

\section{won't capture the bio-}

"For the people who live in these places, this is one way in which science can feel tangible and local." logical meaning that the word 'metabolism' is used to convey, says Muralidhar. "Looking it up on Google Translate, valarchithai came up as a Tamil equivalent of metabolism. This worked perfectly because valarchithai is a compound word consisting of 'grow' (valar) and 'disperse or shatter into pieces' (chithai), so the term would mean 'grow plus disperse", she says. "The agglutinative (putting multiple words together) nature of the Tamil language came to our rescue."

Last June, Inbamuthiah partnered with the Bangalore Life Science Cluster (BLiSC) to organize The Jigyasa Project, a one-night presentation in Bengaluru of science talks and audience-interactive sessions in Kannada, Hindi and Tamil. A second presentation was held in December 2018. Each event included six scientist-presenters, had 100-150 attendees, and covered topics from genetics to intellectual property. The organization plans to continue to hold events every June and December.
The 12 scientists who took part agreed that their presentations were challenging because they required them not just to translate talks into another language, but also to translate the underlying scientific concepts. "I was quite nervous giving a talk in Hindi, and it was a big challenge for me," says Uma Ramakrishnan, a molecular ecologist at the National Centre for Biological Sciences in Bengaluru. "I thought about what I was going to say, and rehearsed it with some of my Hindi-speaking students, just to make sure I was communicating my thoughts correctly.

\section{LOCAL BENEFITS}

Ramakrishnan thinks that the effort to communicate science in languages other than English is very important, especially for field researchers like herself, whose work is local and regional, such as investigating tigers in Rajasthan or biodiversity in the Western Ghats, a biodiversity hotspot along India's west coast. "Doing fieldwork across India, my team and I have often informally communicated our research in Hindi or Malayalam to local people," she says. "For the people who live in these places, this is one way in which science can feel tangible and local. Platforms like Jigyasa provide an opportunity to make this more accessible to a larger audience."

Mahinn Ali Khan, a spokesperson for BLiSC, says that she observed a real sense of camaraderie between the audience and the scientists at Jigyasa. "Speaking in your own language helps you immediately drop the formality and reserve," she says. Khan thinks that, although researchers are eager to engage with non-scientists, the shift to accepting science as a subject that can be discussed in a language other than English still faces some resistance from the public. "At this point, these are passion-driven projects for most of us," agrees Inbamuthiah. 